Abstracta Iranica Abstranica

Revue bibliographique pour le domaine irano-aryen

Volume 28 | 2007

Comptes rendus des publications de 2005

\title{
A Tajik Persian Reference Grammar. Brill, 2005, 521 p., index grammatical, index cyrillique, index arabo- persan.
}

Pollet Samvelian

\section{(2) OpenEdition}

1 Journals

Édition électronique

URL : http://journals.openedition.org/abstractairanica/10642

DOI : 10.4000/abstractairanica. 10642

ISSN : 1961-960X

Éditeur :

CNRS (UMR 7528 Mondes iraniens et indiens), Éditions de l'IFRI

\section{Édition imprimée}

Date de publication : 15 mai 2007

ISSN : 0240-8910

Référence électronique

Pollet Samvelian, «A Tajik Persian Reference Grammar. Brill, 2005, 521 p., index grammatical, index cyrillique, index arabo-persan. », Abstracta Iranica [En ligne], Volume 28 | 2007, document 38, mis en ligne le 18 septembre 2007, consulté le 25 septembre 2020. URL : http://journals.openedition.org/ abstractairanica/10642 ; DOI : https://doi.org/10.4000/abstractairanica.10642

Ce document a été généré automatiquement le 25 septembre 2020.

Tous droits réservés 


\title{
A Tajik Persian Reference Grammar. Brill, 2005, 521 p., index grammatical, index cyrillique, index arabo-persan.
}

\author{
Pollet Samvelian
}

1 Le (persan) tadjik a connu une évolution importante au cours du siècle dernier, sous l'influence du russe, de l'ouzbek et d'autres langues parlées en Asie centrale, mais plus encore, à la suite des deux vagues successives de politique de planification linguistique - la «russification" allant de la fin des années 1920 au début des années 1950 et la «repersanisation», entreprise depuis la fin des années 1980. Comme le souligne l'A., le tadjik d'aujourd'hui doit être appréhendé à travers trois identités distinctes mais complémentaires: en tant que langue définie dans sa relation d'affiliation au persan classique, en tant que variante du persan moderne, au même titre que le persan d'Iran et le dari (d'Afghanistan) et enfin, en tant que groupe de dialectes régionaux, dont certains ont été travaillés en profondeur par les langues turciques.

2 C'est conscient de cette identité complexe que J. Perry a élaboré sa grammaire du tadjik, qui se veut abordable tout en couvrant tous les domaines de la langue. La variante du tadjik décrit est le «tadjik littéraire moderne » (TLM) de l'ère soviétique, soumis aux réformes entreprises depuis les années 1980.

3 L'ouvrage est organisé en cinq grands chapitres, suivant le schéma habituel des grammaires : phonologie et orthographe, morphologie nominale, morphologie verbale, syntaxe, lexique. Les exemples sont transcrits en alphabet cyrillique et en alphabet arabo-persan. Les analyses sont fines et illustrées de nombreux exemples. La terminologie adoptée est précise, compatible avec les travaux linguistiques actuels, sans être pour autant trop technique. Il s'agit d'une référence incontournable sur le tadjik d'aujourd'hui. 
INDEX

Thèmes : 2.2. Langues vivantes et dialectes

\section{AUTEURS}

POLLET SAMVELIAN

CNRS / Mondes iranien et indien - Paris 